\title{
Analysis of Occupational Accidents Based on the Human Factors Analysis and Classification System (HFACS): A Case Study in a Copper Mine
}

\author{
Amin Amiri Ebrahimabadi ${ }^{1}$, Ahmad Soltanzadeh ${ }^{2 *}$ iD, Samira Ghiyasi ${ }^{3}$
}

1. MSc, Department of Health, Safety, and Environment, Faculty of Engineering, Central Tehran Branch, Islamic Azad University, Tehran, Iran.

2. Assistant Professor, Department of Occupational Safety \& Hygiene Engineering, Research Center for Environmental Pollutants, Faculty of Health, Qom University of Medical Sciences, Qom, Iran

3. Assistant Professor, Department of Environmental Engineering, Central Tehran Branch, Islamic Azad University, Tehran, Iran

Article Info

Received: 2020/02/08;

Accepted: 2020/06/06;

ePublished: 2020/07/03

doi $10.30699 /$ jergon.8.1.12

Use your device to scan and read the article online

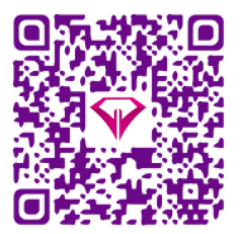

Corresponding Author Ahmad Soltanzadeh Assistant Professor, Department of Occupational Safety \& Hygiene Engineering, Research Center for Environmental Pollutants, Faculty of Health, Qom University of Medical Sciences, Qom, Iran Tel: 09120187486 Email: soltanzadeh.ahmad@gmail.com

\section{ABSTRACT}

Background and Objectives: Occupational accidents are recognized as one of the major concerns in the mining industry. The purpose of this study was to analyze the incidence of occupational accidents in a mine for 10 years using Human Factor Analysis and Classification System (HFACS).

Methods: This cross-sectional study was carried out on 664 mining accidents during 2009-2018. The tools used in this study included accident reporting checklists, human factors analysis and classification system (HFACS), and a team approach to analyze these accidents. Data analysis was performed using SPSS 23.

Results: The accident frequency rate (AFR) was 15.10 \pm 3.34 . The results of 10years accident analysis in this mine based on HFACS model showed that the highest contribution of each parameter to the four layers including unsafe acts, preconditions for unsafe acts, unsafe supervision and organizational influences were respectively devoted to perceptual error $(64.4 \%)$, Physical environment $(29.5 \%)$, inadequate supervision $(59.6 \%)$, and organizational process $(65.6 \%)$. The results of structural equation modeling showed that the AFR is directly and indirectly affected by the layers of the HFACS model $(P<0.05)$. The most significant impact on the AFR was related to the unsafe acts layer.

Conclusion: The findings of this study indicated that all four causal layers of human factors were effective in mine accidents. Since the HFACS model is highly effective for unsafe acts-based accidents analysis, it can be used for future planning to reduce accidents in the mining sector.

Keywords: Occupational accidents, Mine, Human factor analysis and classification system, Structural equation modeling

Copyright (๑) 2020, This is an original open-access article distributed under the terms of the Creative Commons Attribution-noncommercial 4.0 International License which permits copy and redistribute of the material just in noncommercial usages with proper citation.

\section{How to Cite This Article:}

Amiri Ebrahimabadi A, Soltanzadeh A, Ghiyasi S. Analysis of Occupational Accidents Based on the Human Factors Analysis and Classification System (HFACS): A Case Study in a Copper Mine. Iran J Ergon. 2020; 8 (1):12-20 
واكاوى حوادث شغلى براساس سيستم تجزيه و تحليل و طبقلبندى عوامل انسانى (HFACS) مطالعة موردى: معدن مس - مس

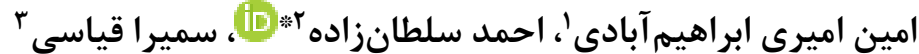

'. كارشناسى ارشد، تروه بهداشت، ايمنى محيطزيست (HSE)، دانشكدة فنى مهندسى، دانشخاه آزاد اسلامى واحد تهران مركزى، تهران، ايران

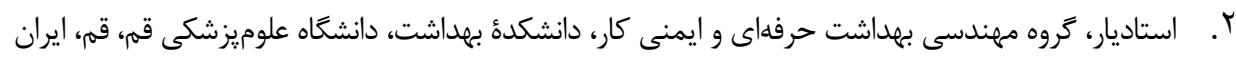

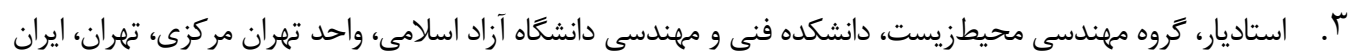

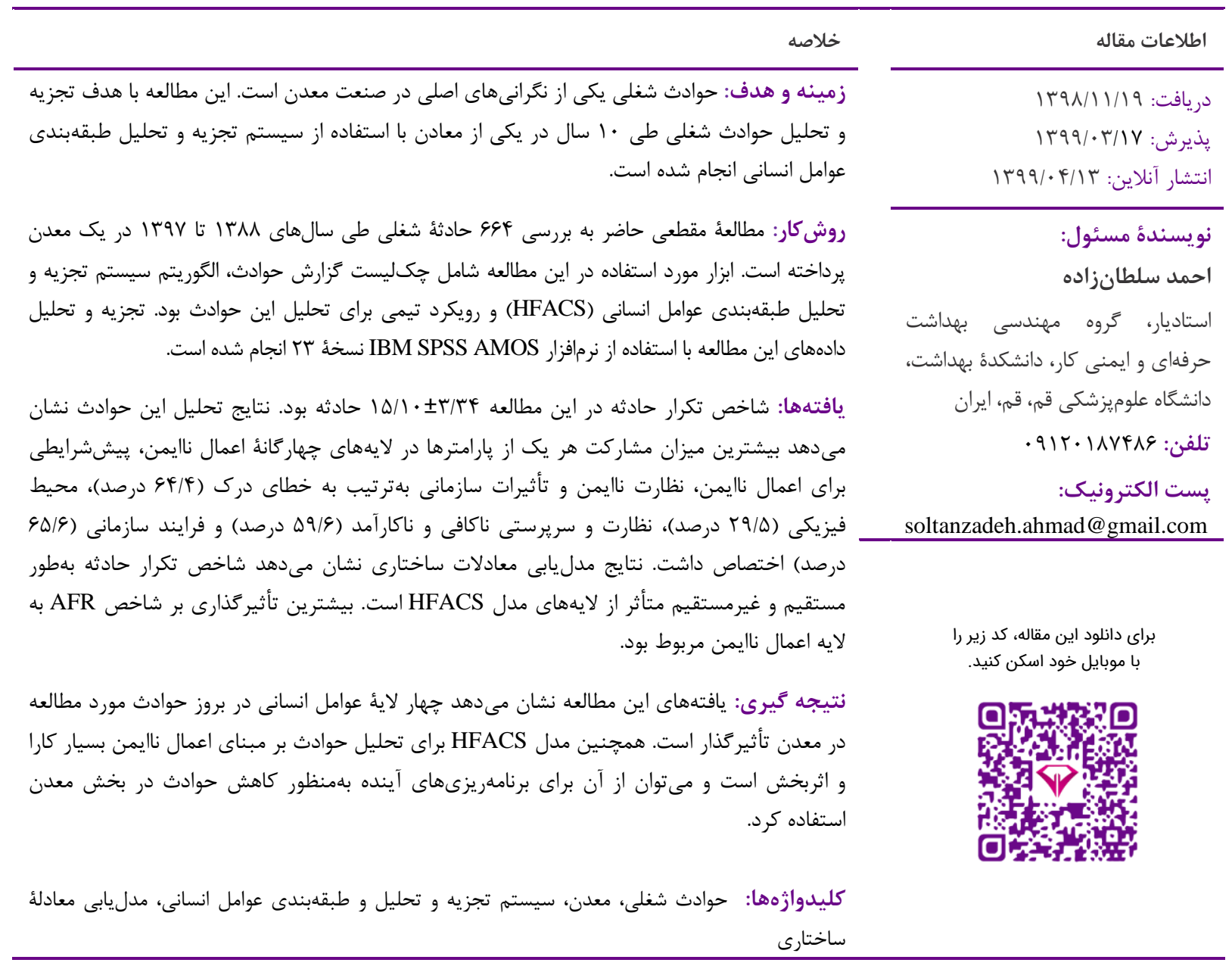

مقدمه

مىدهد هزينٔه اين حوادث بسيار قابلتوجه است؛ بلهورىكه

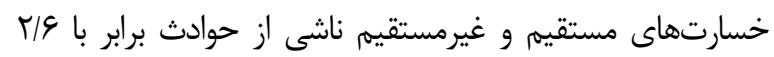

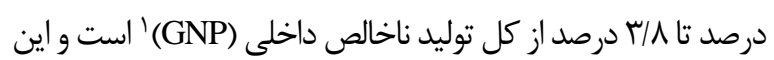

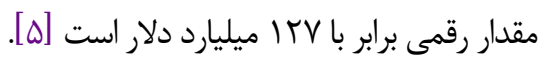
تلفات ناشى از فعاليتهاى موجود در معادن و معدن كارى در

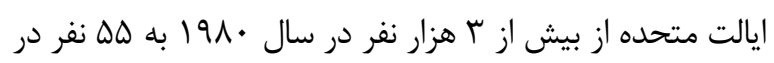

حوادث صنعتى يكى از مشكلات عمده جوامع امروزى است.

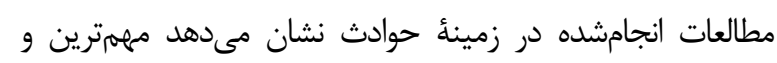

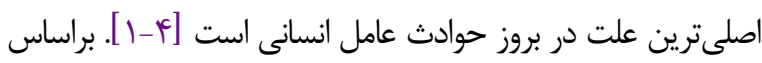

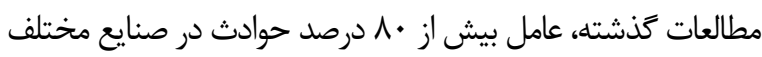
خطاى ايراتور است. همجنين دليل بيش از • •و درصد حوادث

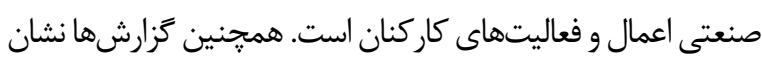

1. Gross National Product 
امين اميرى ابراهيمآبادى و همكاران ا واكاوى حوادث شغلى براساس سيستم تجزيه و تحليل و طبقهبندى عوامل انسانى

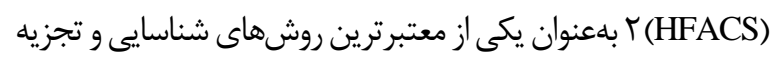
و تحليل اعمال نايمن و خطاى انسانى طراحى و انجام شده است.

\section{روش كار}

مطالعهُ حاضر توصيفى-تحليلى است كه دادههاى حوادث

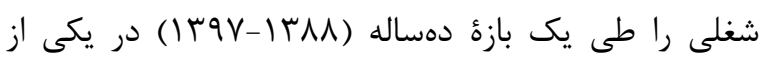

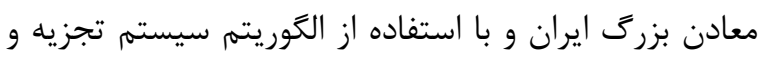

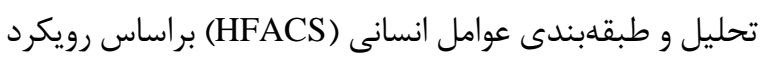

$$
\text { تيمى طى سال 1و ז1 بررسى كرده است. }
$$

\section{جامعه و نمونهُ مطالعه}

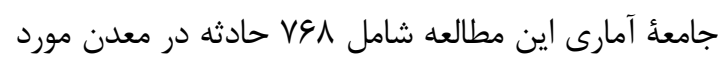

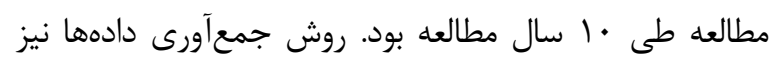
به كمك سرشمارى صورت گرفت. معيار ورود به اين مطالعه ارائه

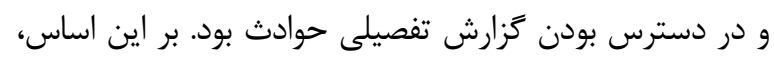

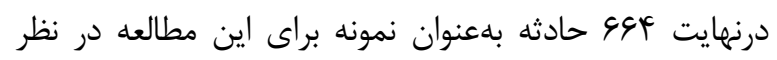
كرفته شد.

\section{جمع آورى و تحليل فنى دادهها}

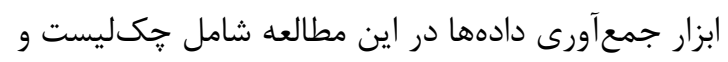

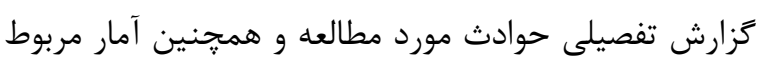

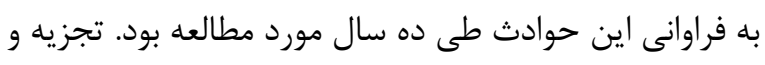

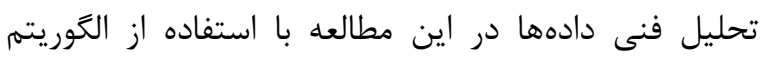
سيستم تجزيه و تحليل و طبقهبندى عوامل انسانى (HFACS) و تحليل جامع اين حوادث بر مبناى اين الكوريتم با استفاده

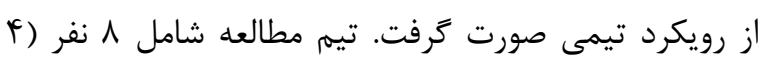

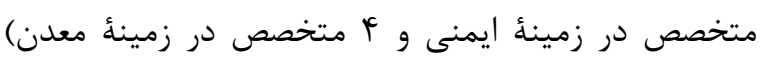

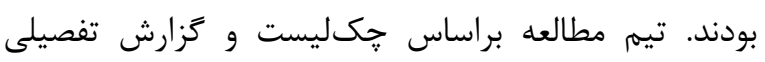

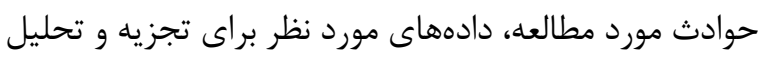

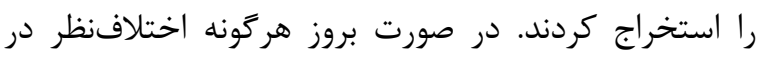

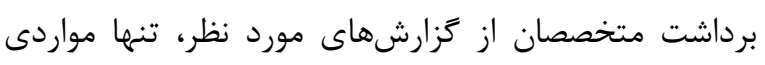

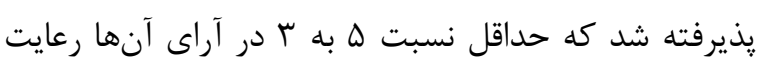

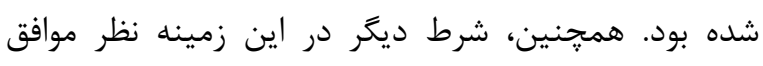

$$
\text { حداقل ب متخصص ايمنى بود. }
$$

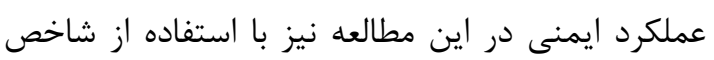

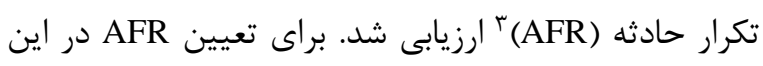

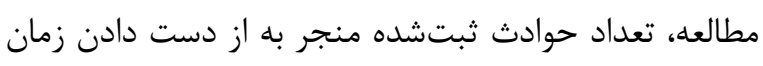

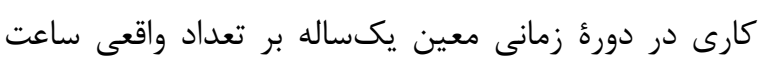

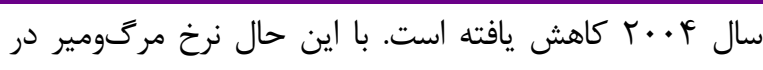

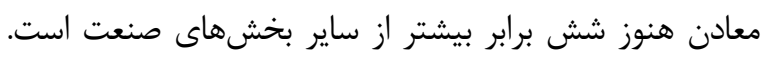

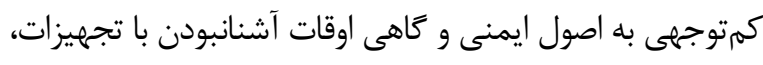

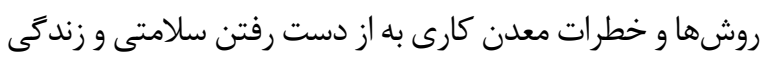

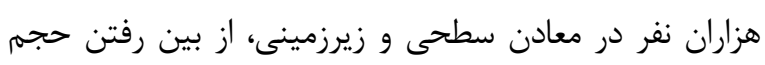

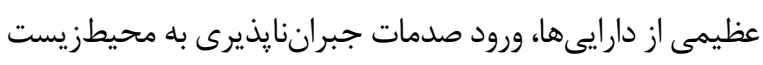

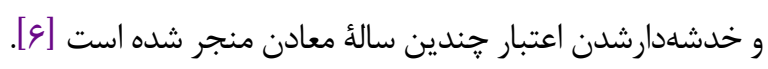
در مطالعه Aghilinejad و همكاران تعداد حوادث شدين سيد

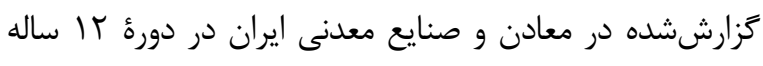

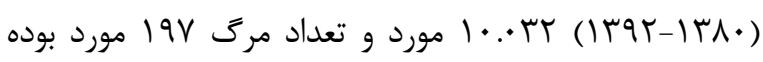

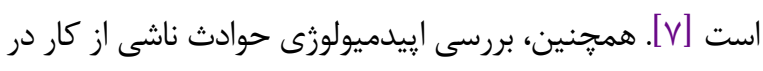

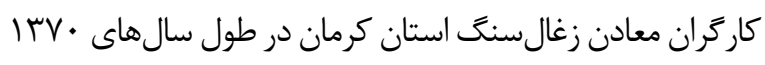

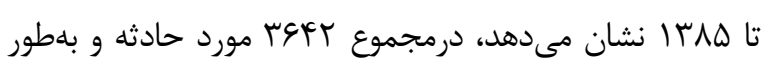

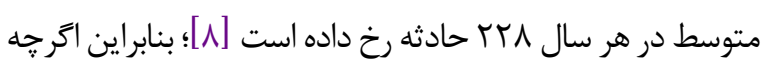

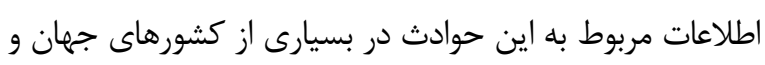

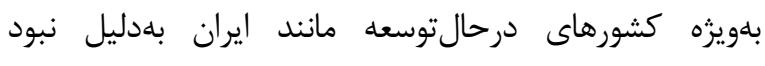

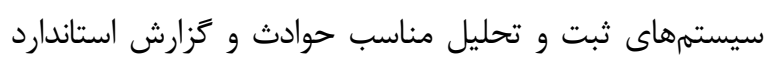

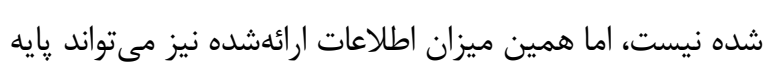

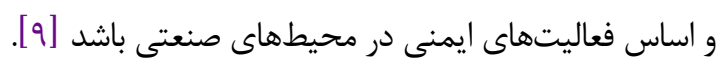

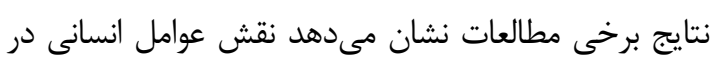

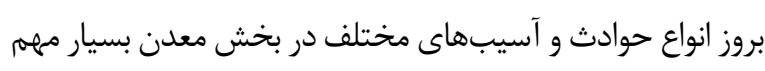

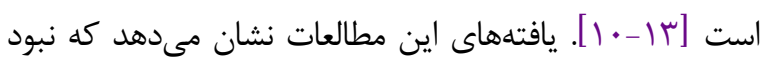

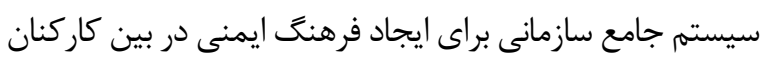

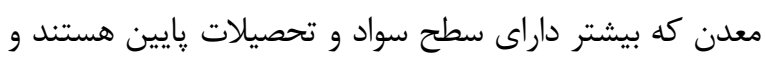

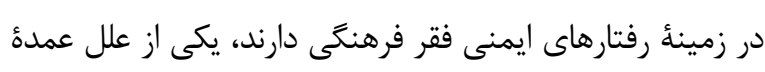

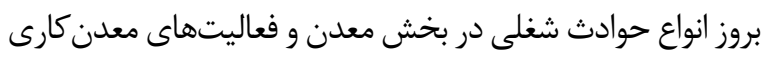

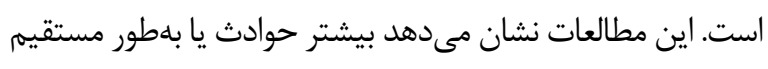

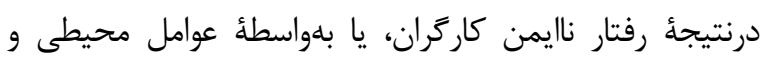

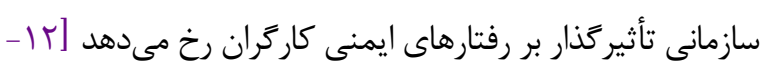

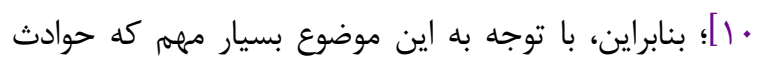

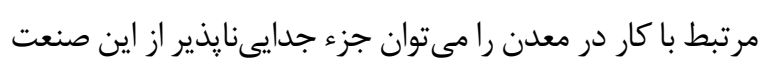

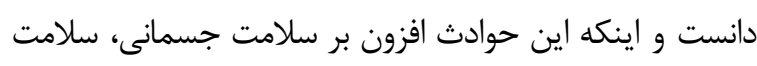

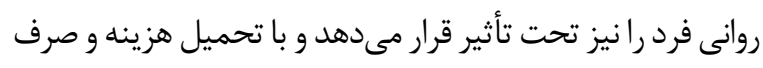

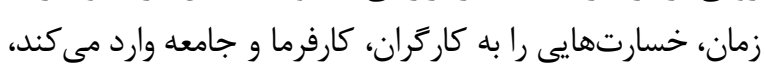

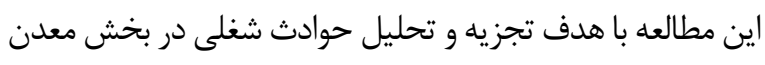

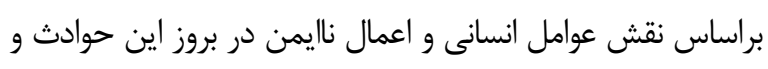
بر مبناى سيستم تجزيه و تحليل و طبقهبندى عوامل انسانى 
مهارت و خطاى تصميمگيرى و زيرسطح تخلفات شامل دو

$$
\text { بخش تخلفات روتين و استثنايى است. }
$$

\section{سطح دوم (ييششرايط براى اعمال نايمن): سطح}

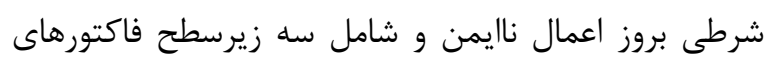
محيطى، شرايط ايراتورها و فاكتورهاى يرسنلى است. زيرسطح فاكتورهاى محيطى شامل بخشهاى تشريط محيط فيزيكى و محيط صنعتى، زيرسطح شرايط ايراتورها شامل حالتهاى ذهاى ذهنى

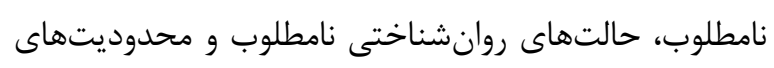
ذهنى يا فيزيكى و زيرسطح فاكتورهاى : يرسنلى شامل مديريت كاركنان (منابع انسانى) و آمادكى فردى است. سطح سوم (نظارت نايمن): سطح نظارت و سريرستى إنى إنى

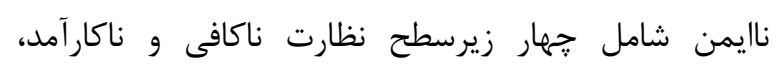

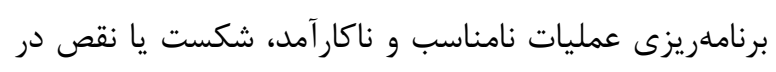
تصحيح مشكل و تخلفات در فعاليتهاى نظارتى است.

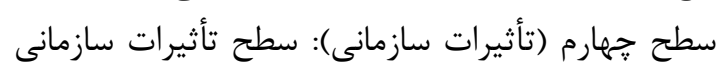

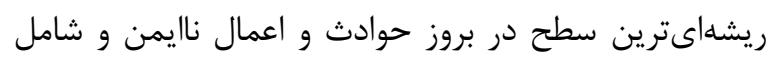
سه زيرسطح مديريت منابع، جو سازمانى و فرايند سازمانى رئى دورئ

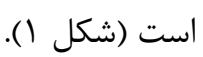

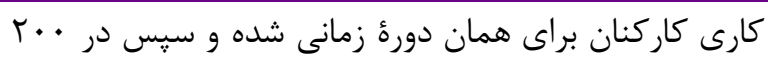

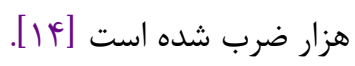

$$
A F R=\frac{\text { Numbers of Registerd Accidents } \times 2 \times 10^{5}}{\text { total Hrs of Workers }}
$$

با توجه به بزرگى معدن و گستردگى فعاليتها در بخشهاى مختلف، شاخص AFR براى هر بخش معدن و براساس سال و

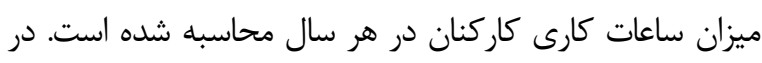
مدلسازى نيز هر حادثه با شاخص متناظر آن تجزيه و تحليل شد.

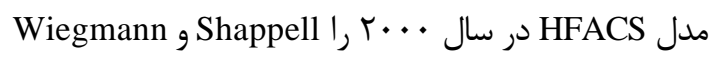
معرفى كردند. اين روش در مطالعات مختلف ارزيابى شده و در

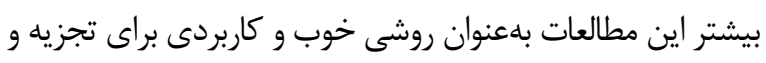

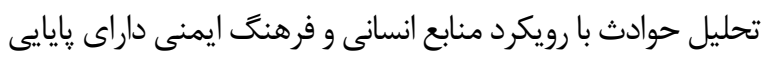

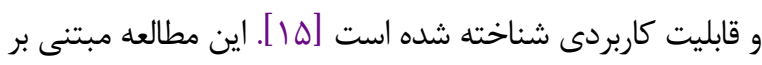
جارجوب الخوريتم HFACS و شامل سطوح زير انجام شده است: سطح اول (اعمال ناايمن): نزديكترين سطح به بروز حوادث و شامل دو زير سطح خطاى انسانى و تخلفات است. زيرسطح خطاى انسانى شامل سه بخش خطاى درك، خطاى زئ سرى

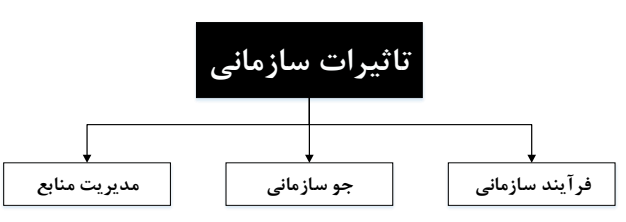

\section{نظارت نايمن}

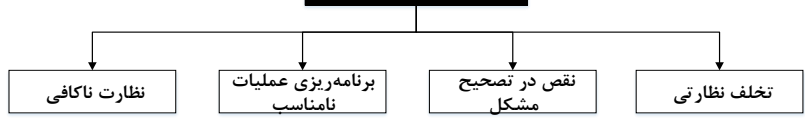

\section{بيش شرايط اعمال}

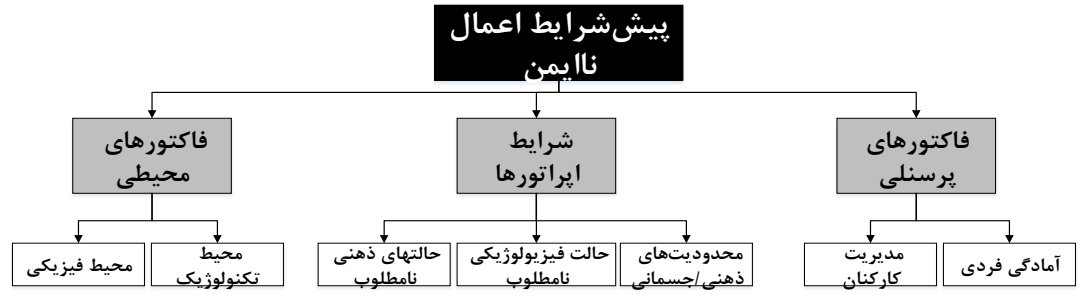

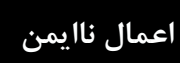

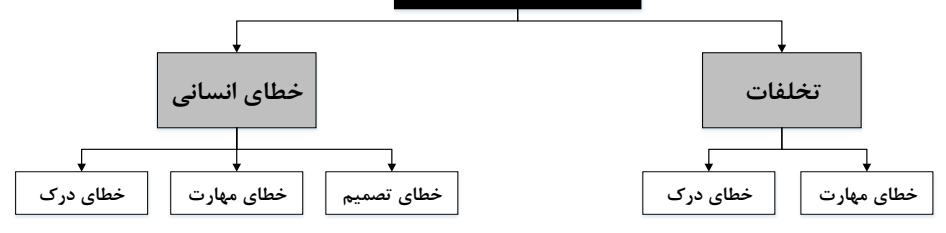

شكل ا. مدل HFACS 


\section{E-ISSN: 2345-5365 | مجله ارتونومى | سال ^، شماره ا، بهار 999}

در معدن نشان مى دهد همأ يارامترهاى هفت كانئ آن در بروز اعمال نايمن و درنتيجه وقوع حوادث مورد مطان مطالعه

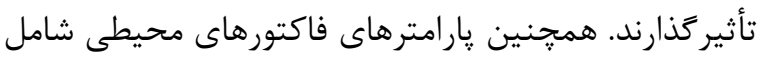

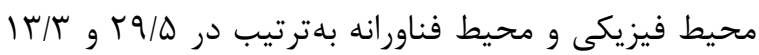
درصد حوادث تأثير كذار بودهاند. يارامترهاى شرايط إيراتورها شامل حالات ذهنى، حالات فيزيولوزيكى و محدوديتهاى

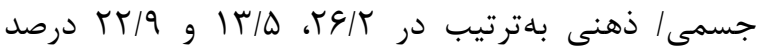

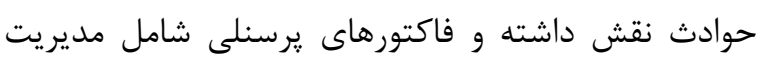

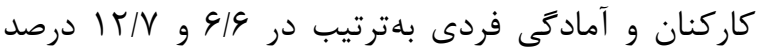

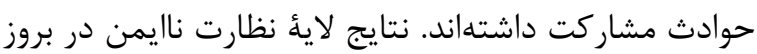
حوادث معدن مورد مطالعه نشان مى دهد كه هر يك از عوامل جهاركانئ اين لايه شامل نظارت و سريرستى ناكافى و ناكارآمد، برنامهريزى عمليات نامناسب، نقص در تصحيح

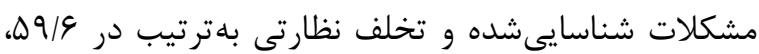

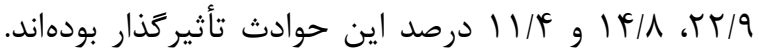
نتايج مربوط به لائ تأثيرات سازمانى در بروز اعمال نايمن و حوادث معدن مورد مطالعه نشان مىدهد هر يكى از اين

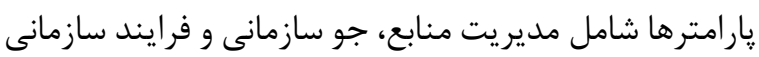

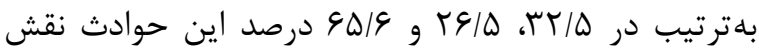
داشتهاند (شكل r r). يافتههاى تحليلى اين مطالعه به ارزيابى ارتباط لايههاى مدل HFACS و شاخص تكرار حوادث مورد مطالعه (AFR)

$$
\text { مربوط است (شكل س). }
$$

نتايج مدلسازى براساس مدليابى معادلات ساختارى نشان مى دهد همأ لايههاى مدل HFACS بلهنوان لايههاى على و

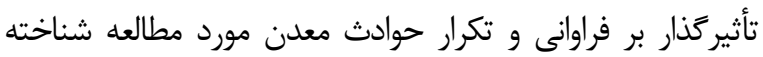
مىشوند (ه • / >P). همجنين اين نتايج نشان مى دهد شاخص تكرار

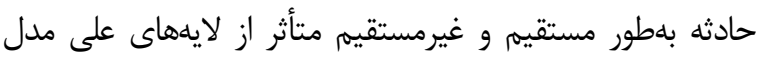

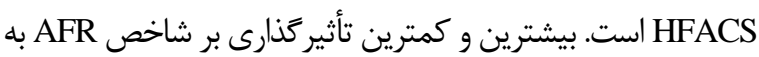

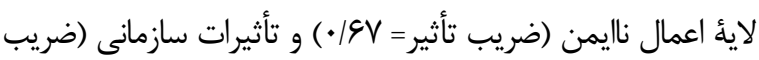

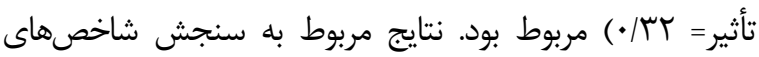
نيكويى برازش مدليابى معادلة ساختارى شاخص تكرار حادثه نيز

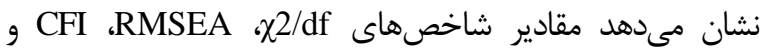
NNFI (TLI)

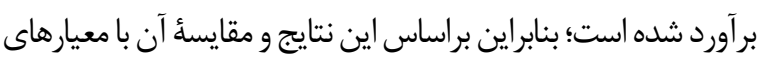
مورد نظر، اين مدل قابلقبول و مناسب است (جدول (1).

\footnotetext{
${ }^{8}$. Normed-Fit Index

9. Non-Normed Fit Index

${ }^{10}$. Tucker-Lewis Index
}

\section{تجزيه و تحليل آمارى دادهها}

تجزيه و تحليل آمارى دادههاى اين مطالعه براساس تحاس

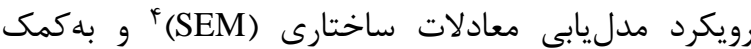

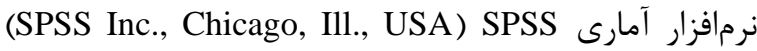

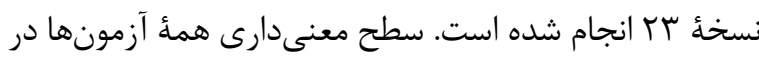

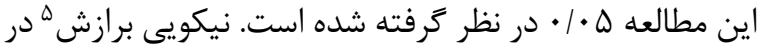
اين مطالعه با استفاده از شاخصهاى كلى RMSEA

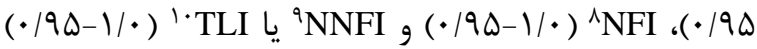
انجام شد. مدليابى معادلات ساختارى تكنيك تحليل

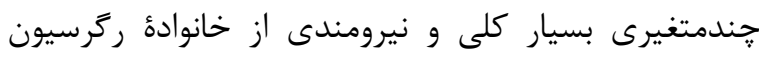

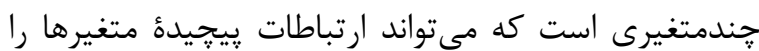
آشكار كند؛ زيرا اين مدل توانايى بهكاركيرى و اجراى ارتباط همزمان عوامل داخلى و خارجى را دارد و علاوه بر اين مى تواند كوامل و متغيرهاى ينهان را وارد مدل كند. استفاده از براى درك ارتباطات يِيجيدة متغيرها و عوامل مختلفى كه مستقيم و غيرمستقيه، ينهان و آشكار در بروز حوادث دخيل بوده و مشار كت دارند بسيار سودمند است [ع 19].

بافته ها

نتايج F94 حادثه طى ده سال، نشان مى دهد كه در اين حوادث VIT نفر آسيب ديدهاند. ميزان شاخص تكرار حادثه

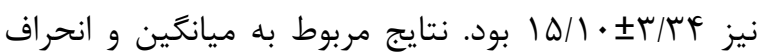
معيار سن و سابقه شغلى افراد حادثهديده در حوادث شغلى نوانى معدن مورد مطالعه بهترتيب

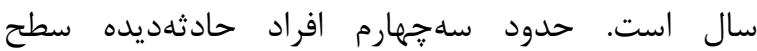

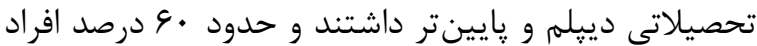
آنها مجرد بودند. نتايج بررسى توصيفى لايئ اعمال نايمن در در درائر

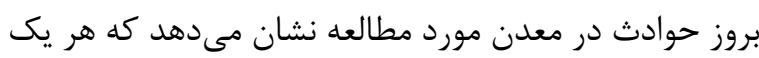

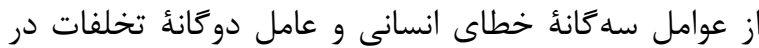
بروز اعمال نايمن و حوادث مورد مطالعه مشاركت داشتند. خطاى درى، خطاى مبتنى بر مهارت و خطاى تصميم خيرى

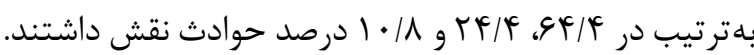
مشاركت تخلفات روتين و استثنايى در بروز اين حوادث

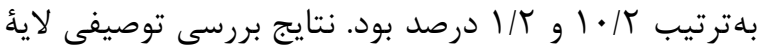

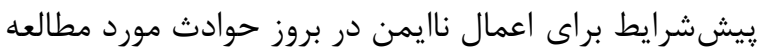

\footnotetext{
${ }^{4}$. Structural Equation Modeling (SEM)

5 . Goodness of Fit

${ }^{6}$. Root Mean Square Error of Approximation
}

7. Comparative Fit Index 


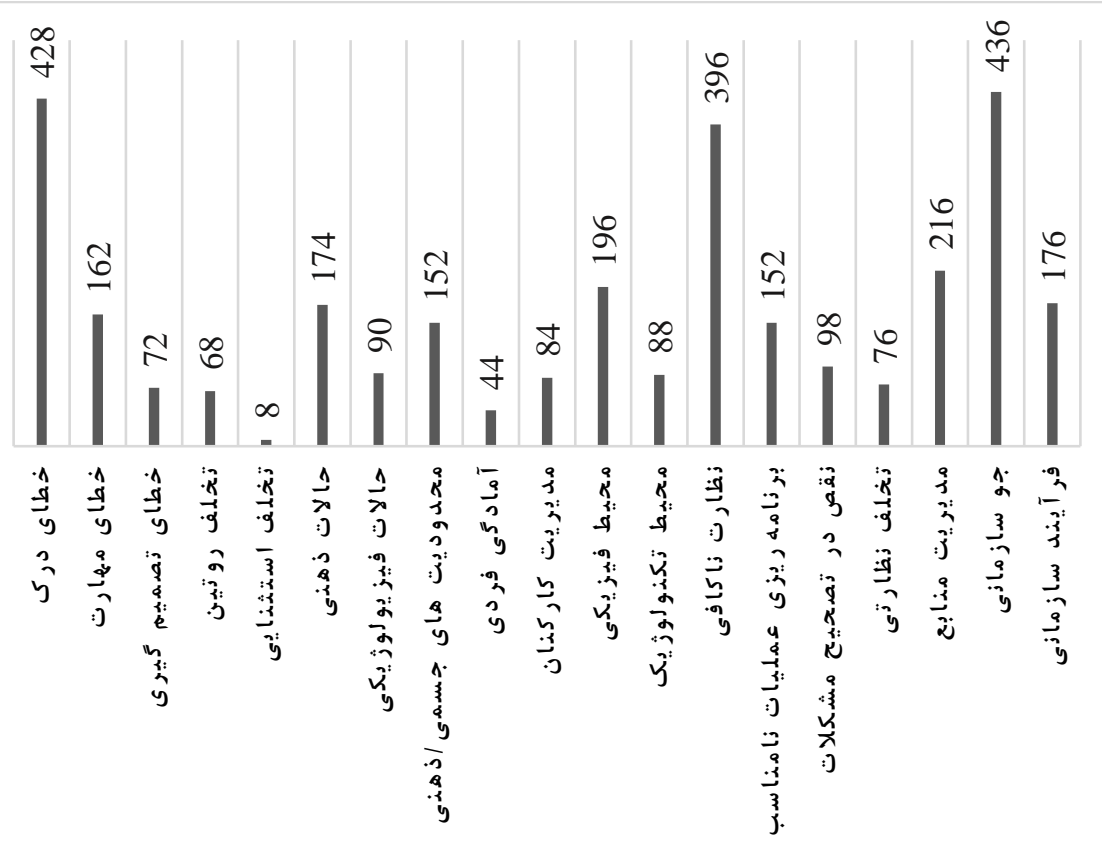

شكل r. نتايج توصيفى ميزان مشاركت عوامل انسانى در بروز حوادث معدن براساس مدل HFACS

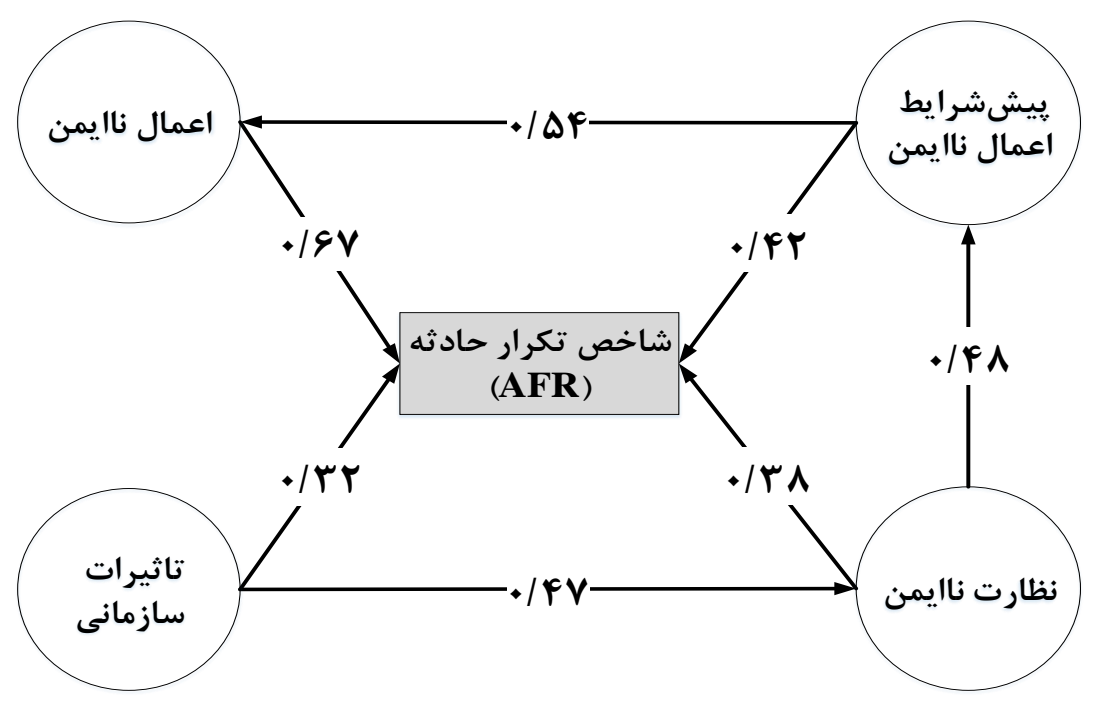

شكل r. نتايج مدل يابى معادلات ساختارى ارتباط شاخص AFR و لايههاى HFACS

جدول (. نتايج توصيفى مطالعهُ بخش دادههاى فردى (r) نفر )

\begin{tabular}{|c|c|c|}
\hline فراوانى (درصد) & \multicolumn{2}{|c|}{ متغير } \\
\hline 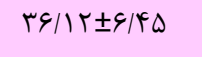 & سن (سال) & \\
\hline$V / T Y \pm \varepsilon / V V$ & سابقه كار (سال) & \\
\hline$\Delta I T(V / / 9)$ & دييلم و پايينتر & \multirow{2}{*}{ سطح تحصيلات } \\
\hline$r \cdots(r N / 1)$ & ليسانس و بالاتر & \\
\hline$r \wedge \Lambda(f \cdot / f)$ & متأهل & \multirow{2}{*}{ وضعيت تأهل } \\
\hline FTF (DQ/G) & مجرد & \\
\hline
\end{tabular}


امين اميرى ابراهيم|آبادى و همكاران ا واكاوى حوادث شغلى براساس سيستم تجزيه و تحليل و طبقهبندى عوامل انسانى

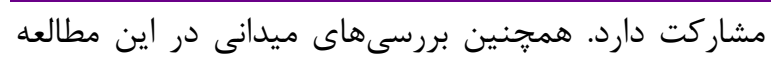

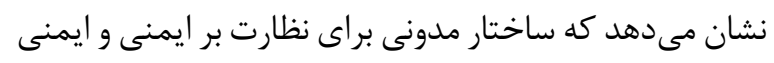

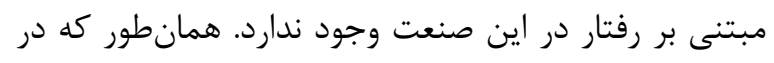

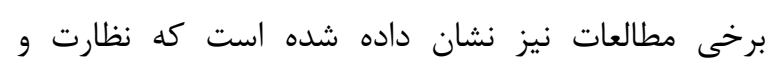

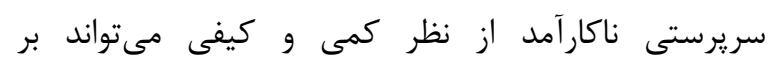

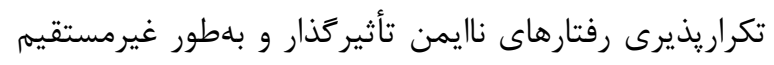

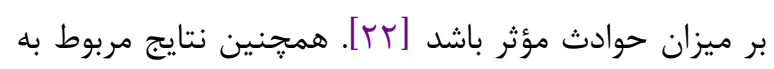

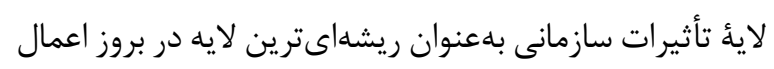

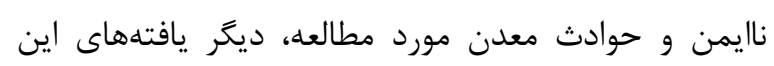

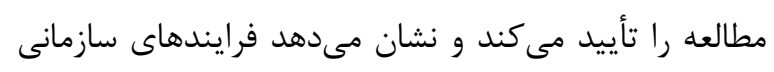

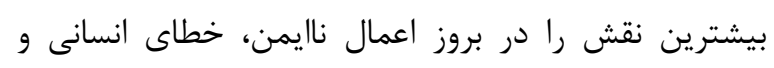
درنتيجه حوادث دارد [سr]. نتايج اين مطالعه با استفاده از رويكرد مدل يابى معادئ دادلات

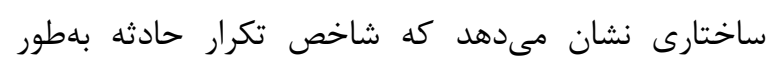

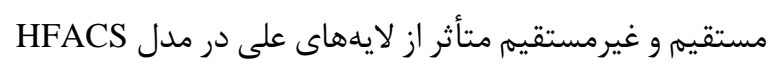

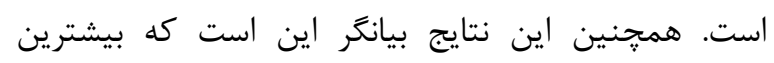

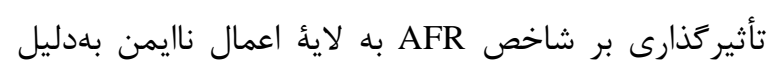

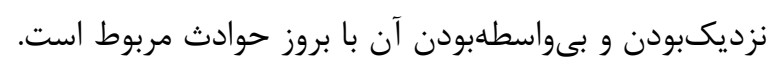
براساس مدل HFACS، تنها لائٔ اعمال ناليمن اثرى برد مستقيم

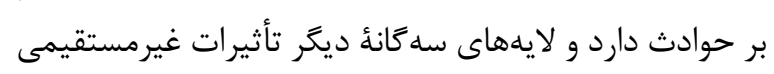

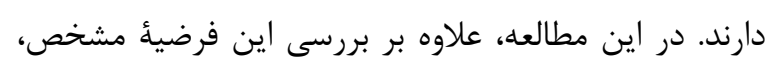

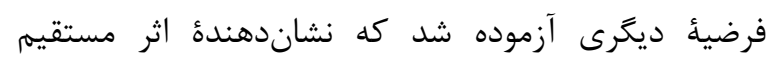

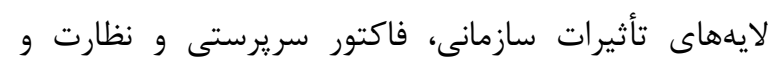

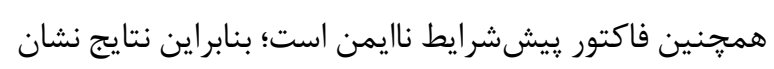

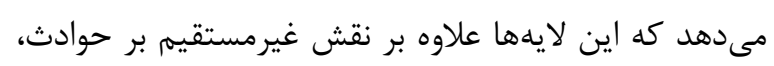

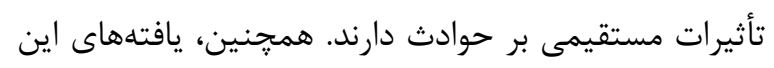

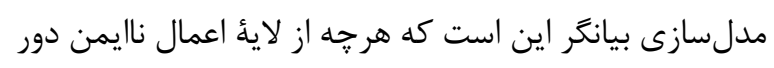

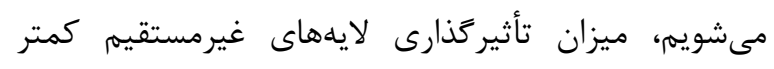
مىشود و به كمك تأثيرات غيرمستقيم بر حوادث مؤثر است.

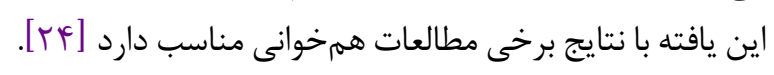

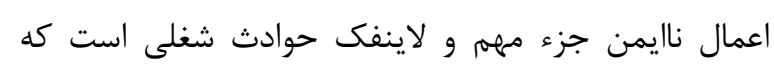

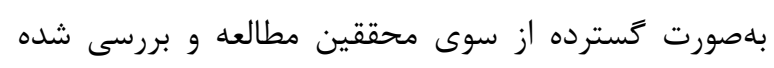

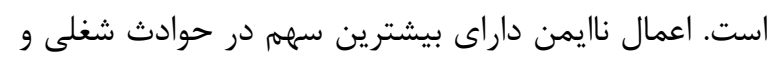

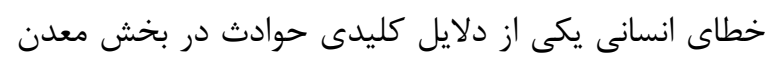

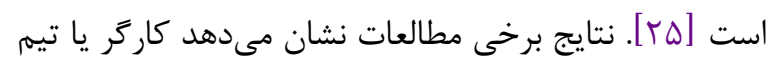

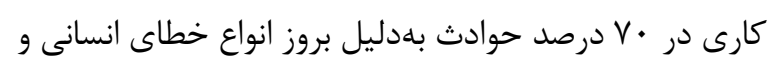

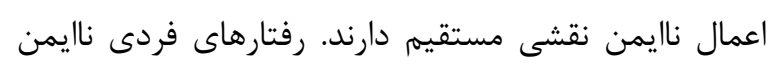

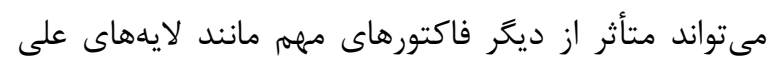

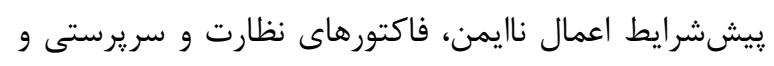

نتايج اين مطالعه نشان مىدهد ميزان شاخص تكرار

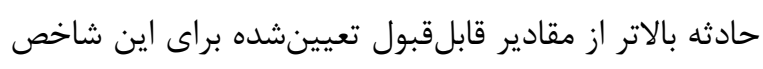

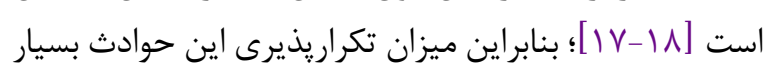

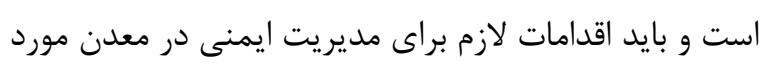

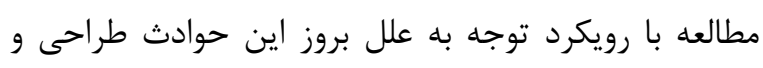

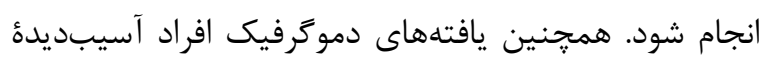

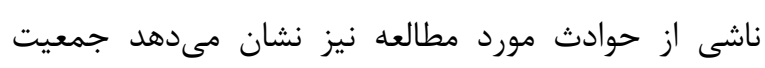

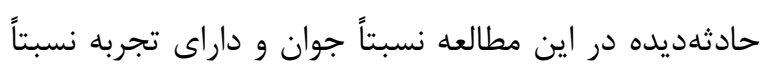

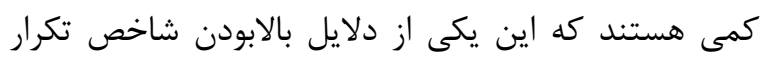
حادثه است [19].

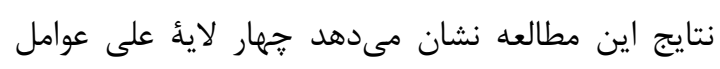

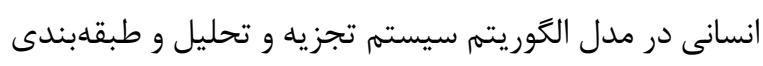

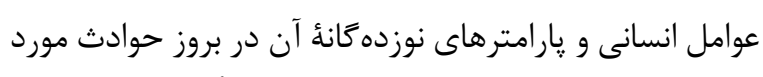

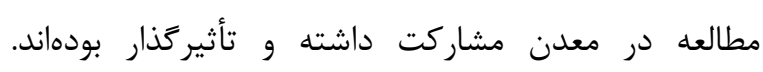

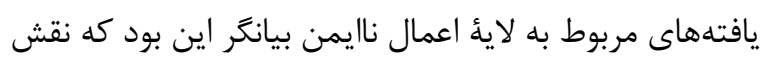

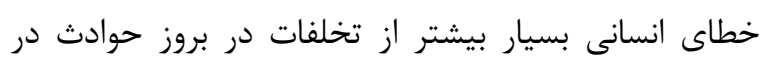

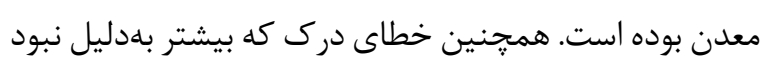

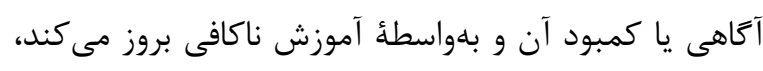

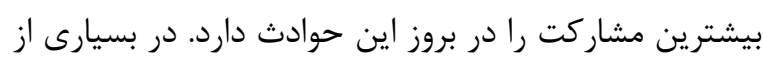

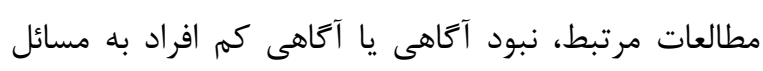

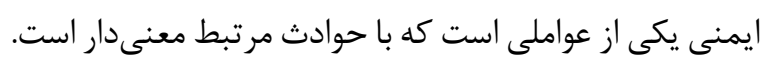

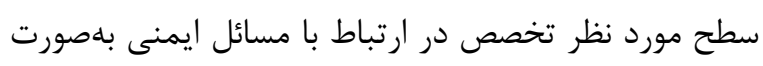

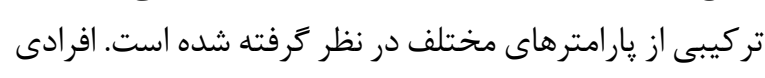

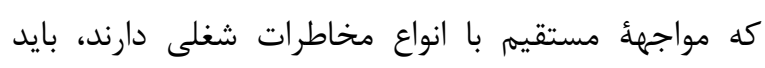

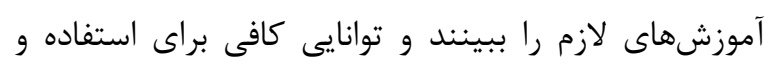

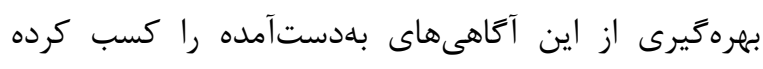

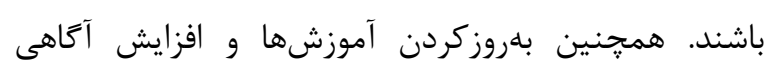

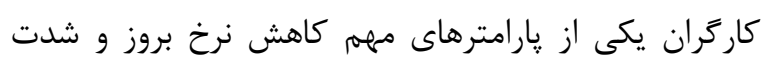

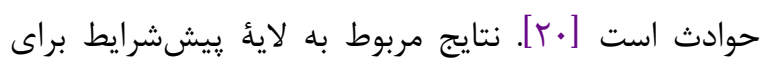

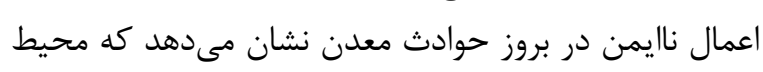

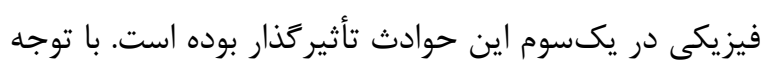

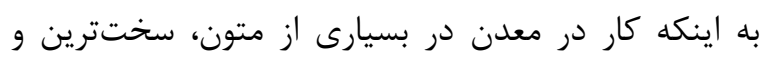

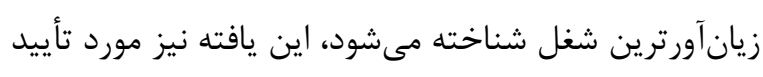

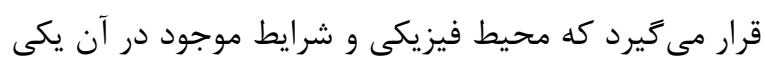

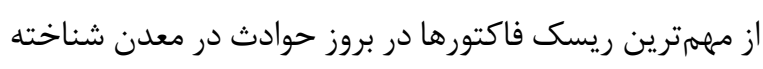

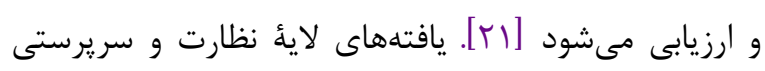

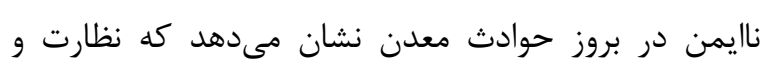

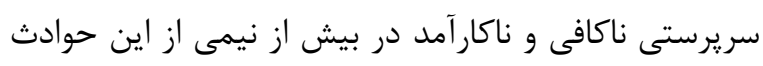




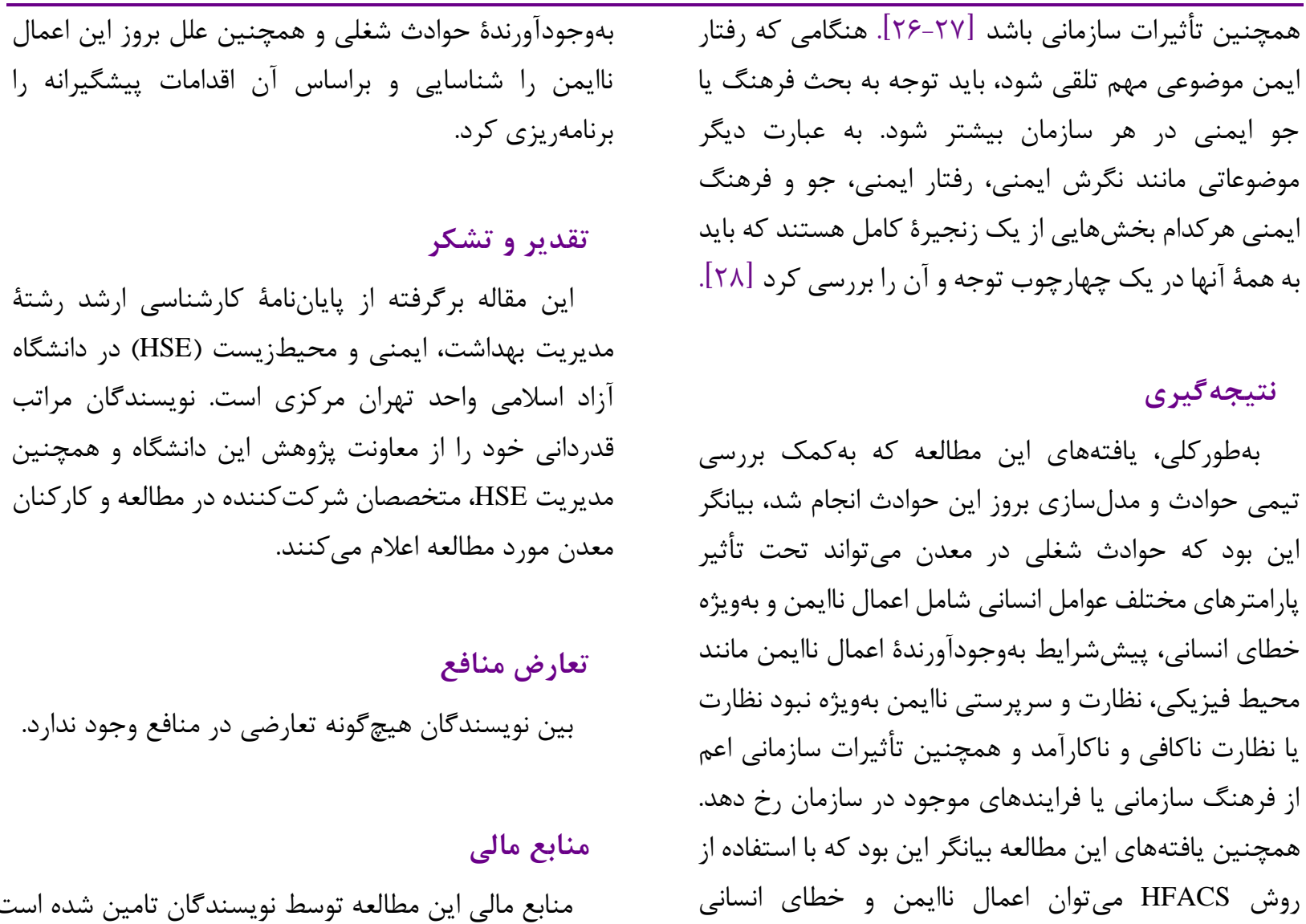

\section{References}

1. Soltanzadeh A, Mohammadfam I, MOGHIM BA, Akbarzadeh M. Studying disabling occupational accidents in the construction industry during two years.

2. Mohammadi H, Soltanzadeh A, Heidari H, Mohammadbeygi A, Mahdinia M, Rahimi J. Factor Analysis of Risk Variables Affecting Occupational Injuries: A Field Study in Construction Projects. Journal of Occupational Hygiene Engineering Volume. $2019 \quad$ Mar 1;5(4):50-6. [DOI:10.29252/johe.5.4.50]

3. Arassi M, Mohammadi H, Motamedzade M, Kamalinia M, Mardani D, Mohammadi Beiragani M, et al. The Association between psychosocial factors and Occupational Accidents among Iranian Drilling Workers. Journal of Ergonomics. 2014;2(1):36-45.

4. Pakdel E, Omidvari M. Investigating the Effects of Human Personality on Human Reliability and Accident Frequency Using DISC and HEART Technique in Automotive Industries. Iranian Journal of Ergonomics. 2017 Jun 15;5(1):26-35. [DOI:10.21859/joe-05014]

5. Santos AJ, Rebelo EL, Mendes JC. Towards better prevention of fatal occupational accidents in Portugal. International Labour Review. 2018 Sep;157(3):40933. [DOI:10.1111/ilr.12114]

6. Homer AW. Coal mine safety regulation in China and the USA. Journal of Contemporary Asia. 2009 Aug 1;39(3):424-39. [DOI:10.1080/00472330902944511]

7. Aghilinejad M, Kouhpayezade J, Kazem Noori M, Golabadi M. Association of age and work experience with work-related injuries in mining and mineral industries in Iran 2003-2011. Razi Journal of Medical Sciences. 2013 Feb 1;19(104).

8. Khodabandeh S, Haghdoost A, Khosravi Y. Epidemiology of work-related Accidents in Kerman Coal Mines during 1991-2006. Iran Occupational Health. 2012 Jan 1;8(4).

9. Soltanzadeh A, Mohammadfam I, Moghimbeygi A, Ghiasvand R. Exploring causal factors on the severity rate of occupational accidents in construction worksites. International journal of civil engineering. 2017 Oct 1;15(7):959-65. [DOI:10.1007/s40999017-0184-9]

10. Simpson G, Horberry T. Understanding human error in mine safety. CRC Press; 2018 Apr 17. [DOI:10.1201/9781315549194]

11. Palka D. The role and importance of training for improving the safety and awareness of the technical staff in the mining plant. InCBU International Conference Proceedings 2017 Sep 24 (Vol. 5, pp. 1195-1198). [DOI:10.12955/cbup.v5.1095]

12. 12. Papic L, Kovacevic S. Human factor in mining machines maintenance operations. In2016 Second International Symposium on Stochastic Models in 
Reliability Engineering, Life Science and Operations Management (SMRLO) 2016 Feb 15 (pp. 456-465). IEEE. [DOI:10.1109/SMRLO.2016.80]

13. Samadi H, Kalantari R, Mostafavi F, Zanjirani fFarahani A, Bakhshi E. Using the Need for Recovery Scale to Assess Workload in Mine Workers and Its Relationship With Demographics. Iranian Journal of Ergonomics. 2017 Mar 15;4(4):1-7. [DOI: 10.21859/joe-04041]

14. Anastasopoulos PC. Random parameters multivariate tobit and zero-inflated count data models: addressing unobserved and zero-state heterogeneity in accident injury-severity rate and frequency analysis. Analytic methods in accident research. 2016 Sep 1;11:17-32. [DOI:10.1016/j.amar.2016.06.001]

15. Shappell SA, Wiegmann DA. Applying Reason: The human factors analysis and classification system (HFACS). Human Factors and Aerospace Safety. 2001.

16. Xia Y, Yang Y. RMSEA, CFI, and TLI in structural equation modeling with ordered categorical data: The story they tell depends on the estimation methods. Behavior research methods. 2019 Feb 15;51(1):40928. [DOI:10.3758/s13428-018-1055-2] [PMID]

17. Lim S, Oh AR, Won JH, Chon JJ. Improvement of inspection system for reduction of small-scale construction site accident in Korea. Industrial health. 2018 Jun 23. [DOI:10.2486/indhealth.2018-0033] [PMID] [PMCID]

18. Soltanzadeh A, Heidari HR, Mahdinia M, Mohammadi H, Mohammadbeigi A, Mohammadfam I. Path analysis of occupational injuries based on the structural equation modeling approach: a retrospective study in the construction industry. Iran Occupational Health. 2019;16(3):47-57.

19. Mohammadfam I, Soltanzadeh A, Moghimbeigi A, Akbarzadeh M. Modeling of individual and organizational factors affecting traumatic occupational injuries based on the structural equation modeling: a case study in large construction industries. Archives of trauma research. 2016 Sep;5(3). [DOI:10.5812/atr.33595] [PMID] [PMCID]

20. Leão CP, Costa S. Safety Training and Occupational Accidents-Is There a Link? InInternational Conference on Applied Human Factors and Ergonomics 2019 Jul 24 (pp. 536-543). Springer, Cham. [DOI:10.1007/978-3-030-20145-6_53]

21. Bonsu J, Van Dyk W, Franzidis JP, Petersen F, Isafiade A. A systemic study of mining accident causality: an analysis of 91 mining accidents from a platinum mine in South Africa. Journal of the Southern African Institute of Mining and Metallurgy. 2017 Jan;117(1):59-66. [DOI:10.17159/24119717/2017/v117n1a9]

22. Liu R, Cheng W, Yu Y, Xu Q. Human factors analysis of major coal mine accidents in China based on the HFACS-CM model and AHP method. International journal of industrial ergonomics. 2018 Nov 1;68:2709. [DOI:10.1016/j.ergon.2018.08.009]
23. Mirzaei Aliabadi M, Aghaei H, Kalatpour O, Soltanian AR, Nikravesh A. Analysis of human and organizational factors that influence mining accidents based on Bayesian network. International journal of occupational safety and ergonomics. 2018 Apr 25:18. [DOI:10.1080/10803548.2018.1455411] [PMID]

24. Zhang Y, Jing L, Bai Q, Liu T, Feng Y. A systems approach to extraordinarily major coal mine accidents in China from 1997 to 2011: an application of the HFACS approach. International journal of occupational safety and ergonomics. 2019 Apr 3;25(2):181-93. [DOI:10.1080/10803548.2017.1415404] [PMID]

25. Kumar P, Gupta S, Gunda YR. Estimation of human error rate in underground coal mines through retrospective analysis of mining accident reports and some error reduction strategies. Safety Science. 2020 Mar 1;123:104555. [DOI:10.1016/j.ssci.2019.104555]

26. Shirali GA, Karami E, Goodarzi Z. Human errors identification using the human factors analysis and classification system technique (HFACS). Health and Safety at Work. 2013 Dec 15;3(3):45-54.

27. Harris D, Li WC. Using Neural Networks to predict HFACS unsafe acts from the pre-conditions of unsafe acts. Ergonomics. 2019 Feb 1;62(2):181-91. [DOI:10.1080/00140139.2017.1407441] [PMID]

28. Rubin M, Giacomini A, Allen R, Turner R, Kelly B. Identifying safety culture and safety climate variables that predict reported risk-taking among Australian coal miners: An exploratory longitudinal study. Safety Science. 2020 Mar 1;123:104564. [DOI:10.1016/j.ssci.2019.104564] 